\title{
LISSAUER'S DEMENTIA PARALYTICA CONTRIBUTION TO THE STUDY OF ITS DIAGNOSIS AND PATHOGENESIS
}

\author{
BY \\ A. J. GALBRAITH and A. MEYER \\ From the Central Pathological Laboratory, L.C.C. Mental Health Services.
}

(RECEIVED 16TH MARCH, 1942)

\section{Introduction}

CASES of general paralysis of the insane in which "focal " symptoms are a prominent feature, and which show circumscribed atrophy of parts of one or both cerebral hemispheres, have been grouped under the heading of Lissauer's Dementia Paralytica. Lissauer and Storch published their paper in 1901, but in Alzheimer's (1904) famous monograph there is mention of a number of cases of this condition which had been recorded prior to this. Since then further cases have been described. In 1932 Merritt and Springlova reviewed 35 cases previously published in the literature, and added eight cases which they had personally studied. In 1936 Ogino reported on three cases, and a year later Malamud's (1937) paper contained a description of four further cases. The latest studies on this subject by Dalke (1938) and Divry (1940) are unfortunately not available for comment in this paper.

The definition of the clinical syndrome and the description of the pathological findings, in cases of Lissauer's Dementia Paralytica, given by Merritt and Springlova, represents the generally accepted view on the condition up to the present time. These authors came to the conclusion "that Lissauer's Dementia Paralytica should be suspected in every case of general paralysis with apoplectiform or unilateral convulsions, especially when these are followed by localizing signs, e.g. hemiplegia, aphasia, hemianopia, etc."

The cardinal pathological feature, as previously indicated, is the presence of one or more areas of macroscopically apparent local atrophy, which are, with few exceptions, e.g. cases of Buder (1903) and Bielschowsky (1920) situated in the so-called "posterior" parts of the cortex. Indeed Alzheimer had already referred to the Lissauer type as general paralysis of the posterior cerebral cortex. Merritt and Springlova, and later Ogino, have regarded the distribution of the atrophic areas in most cases as being intimately related to that of the middle cerebral artery. The histological picture in the regions of the cortex which are not markedly atrophic is one of the usual G.P.I. process, often comparatively mild. On the other hand, the areas of local atrophy 
present features which differ considerably from those seen in the non-atrophic regions. The most prominent, and according to Malamud the essential change found in the atrophic areas is status spongiosus, first described by Fischer in 1911. This is characterized by extensive loss of all the component parts of the parenchyma, with an imperfect replacement by glial tissue. The end result is the formation of a coarse glial reticulum, lacking in both " ground substance " and cellular elements. It is frequently laminar, involving especially layers II and III. In the white matter of the atrophic areas a somewhat analogous state of affairs may be present. Thus demyelinization followed by gliosis frequently results in a typical status spongiosus. Evidence of an inflammatory reaction is usually less than in the non-atrophic regions, and the iron reaction ("Paralyseeisen ") is characteristically weak or may even be negative.

The problem of pathogenesis in Lissauer's Dementia Paralytica has been widely discussed since the original publication of Lissauer and Storch, and various theories have been proposed. The trend in recent years has been to introduce a vasomotor factor (Merritt and Springlova), or to explain the pathological changes in terms of colloid chemistry (von Braunmühl, 1932, 1933). Since our own case seems to be of special interest with regard to pathogenesis, it will be described first, and its significance in relation to the pathogenetic problem will be discussed later.

\section{Clinical History}

Mrs. D. B. Aged 40.

Family History.-Negative for mental disorder.

Personal History.-The patient was stated to be obstinate and subject to " tantrums" during childhood. Before her marriage she was employed as a dressmaker. She took no serious interest in the opposite sex until she met her future husband whom she married in 1924, when she was 27 years old. There are four children by this marriage. During her adult life she was described as being of a "cheerful and affectionate nature, but inclined to be irritable and obstinate." She had apparently no special interests beyond her home and had few friends.

No history of alcoholism.

Scarlet fever when æt. 34.

\section{History of Present Illness}

The patient's husband was killed in an accident in 1931 (Pt. æt. 34). Following the death of her husband she seemed to lose interest in everything and became neglectful of her person and her children. In 1934 she became subject to fits of excitement during which she would throw things at anyone who happened to be near at hand. She was eventually removed from home and admitted to Bexley Hospital on 5/7/34. At this time she was described as being garrulous and excitable. She recounted how for several weeks previously she had felt confused and had " terrible feelings in her mind" and got so "worked up" that she "shook the children and broke things." She finally felt that she would have to kill both herself and the children. Physical examination showed no abnormalities in the central nervous system or elsewhere.

Blood W.R., negative. M.K.R., negative (15/7/34).

Her mental condition gradually settled down and she was discharged from 
hospital on $24 / 11 / 34$, when it was stated that "she was now probably returned to her normal-an unstable, irrational, self-opinionated woman."

On her return home it was obvious that she had made no real " recovery." She continued to neglect her children, home, and person. She was depressed and unsocial. She refused to eat any food other than that cooked by herself. The children were eventually removed to the care of the N.S.P.C.C. and she became increasingly depressed, agitated, and suspicious. On one occasion she said that a policeman was standing looking at the house when apparently there was no one to be seen. She was admitted to the Maudsley Hospital on 27/9/37. Her mental and physical condition at this time are summarized as follows: "She is apathetic, mistrustful, and slightly paranoid. Her condition is faulty and her memory is very defective, especially for events since 1934 . Her powers of retention and her general knowledge are poor. She appears to realize that she is ill but has no proper insight into her condition. Her movements are clumsy, limbs are spastic, and show coarse tremors. The right pupil is irregular and smaller than the left (outline regular). Both pupils react weakly to light, but give normal consensual responses. She is faulty in her habits."

\section{Clinical Investigation of Focal Symptoms by Dr. W. Mayer-Gross}

Besides marked signs of general mental deterioration the patient showed symptoms of circumscribed defects. During frequent examinations between 18th and 27th October, 1937, she became more co-operative although she was always slightly perplexed and often bewildered when she did not succeed in any individual test.

Neurological examination revealed rigidity in both arms, especially on the left side; latent paresis of the left arm which tended to drop when the eyes were closed. All deep reflexes were slightly increased on the right side. Adiadochokinesis was present, being more marked on the left side.

Investigation of the visual functions revealed a left-sided defect almost amounting to hemianopia. There was a general impairment of visual attention, especially in the periphery. No colour scotoma was found. Optokinetic nystagmus was negative to the right; the naming of colours was undisturbed as was the selection of named colours. There was a tendency to pick out details from scenic pictures, but no visual agnosia for objects. The patient was able to read the time from a clock.

There was severe finger agnosia. Imitation of finger postures was impossible. The distinction between right and left was aboiished.

Visual counting was severely impaired. As regards mental arithmetics, only simple sums and tables could be done correctly; problems such as multiplying 16 by 2 or dividing 26 by 2 could not be accomplished. The reading of numbers was correct, but there was a typical number-writing disturbance in that she wrote, e.g. 311 as $300+11$.

She was unable to repeat a rhythm containing more than three elements tapped out on the table.

Investigation of her writing ability revealed literal agraphia especially in letters which are not often used, such as $z, q u, k$.

Words were correctly spelled, but wrongly written. There was a tendency to perseveration and inability to copy written words which she was able to read.

No object apraxia was found in simple activities, such as using soap, the water tap, etc. She was unable, however, to use a tape measure and failed almost completely in pretending purposeful movements, such as catching a fly, playing the piano, etc. Expressive movements of face and hands were unimpaired.

She was completely unable to copy a square from matches, a simple pattern of coloured mosaics, or a " tower" built from four coloured bricks despite many efforts. Nor was she able to copy a simple drawing. In this and in writing "closing in" was a marked feature. 
The investigation thus clearly demonstrated left-sided hemianopia, disturbance of visual attention, constructional apraxia, drawing disturbance, finger agnosia, inability to distinguish right from left, agraphia, and acalculia. All the symptoms were indicative of a lesion in the parieto-occipital region, preponderantly, but not exclusively of the left hemisphere.

\section{Electro-encephalogram (Mr. Grey Walter)}

Nothing definitely abnormal but occasional rapid high potential discharges from the parietal regions of both sides.

$X$-ray of Skull.-Normal appearance.

Blood.-W.R., negative (29/9/37).

Cerebrospinal Fluid.-W.R., negative; cells, 1 per c.mm.; protein, $55 \mathrm{mgm}$. per cent.; Lange, $5532100(1 / 10 / 37)$.

Cells, 1 per c.mm.; protein, 60 mgm. per cent.; Lange, 55432100 (15/10/37).

Blood counts and urine examination normal.

Discharged to Observation Ward on 19/11/37_“" Unimproved."

Admitted to Bexley Hospital on 26/11/37. Her mental state at this time was characterized by extreme confusion. She was completely disorientated for time and place and showed instantaneous amnesia. She thought that she was in the Maudsley Hospital and had been there for 14 months. She stated that she saw her husband (dead for 7 years) on the previous day and had slept with him on that night. She was extremely suggestible and fabricated on the slightest pretext. With a little suggestion she could be made to give the most fantastic accounts of herself, e.g. that the Prime Minister had recently taken her to a dinner and given her an opal ring which was now on her finger (the finger in question being ringless). She was restless and frequently attempted to strip herself and wander about the ward. She frequently sat up in bed saying repeatedly: "I feel sleepy; may I go to sleep?" She held herself rigidly and was resistive to attentions. She was oblivious of personal needs and required constant care and supervision by the nursing staff. On admission her physical condition was in accordance with the facts reported from the Maudsley Hospital. The spasticity of the limbs was especially noted, and the left arm was stated to be more rigid than the right. No definite Plantar response was elicited in either foot, but a definitely " positive" reaction to Oppenheim's test was obtained, and there was a tendency to spontaneous knee clonus.

She remained noisy, restless, and confused. On 26/12/37 she suddenly collapsed, became extremely pallid, and died within a few minutes.

\section{Pathological Investigation}

Only the brain was available for investigation. Its weight taken at the post mortem was $975 \mathrm{gm}$. The meninges were thickened and opaque. The cerebral convolutions appeared to be moderately atrophic, but there was no major circumscribed atrophy. The arteries at the base were normal. On dissection no gross lesion was seen. The lateral ventricles were slightly enlarged.

Microscopic examination revealed changes characteristic of dementia paralytica. They consisted of infiltrations in the meninges and around precapillaries and capillaries of the grey matter with plasma cells, lymphocytes, and occasional mast cells. Furthermore diffuse microglial proliferation, iron deposits in adventitial and microglial cells, and a varying degree of degeneration and outfall of nerve cells were found. These changes were seen in the cerebral cortex, caudate nucleus, putamen, and hypothalamus, whereas they were negligible in the globus pallidus, grey centres of the midbrain, brain stem, and cerebellum. 
The iron rection in these various regions was not uniformly positive. Only in the putamen and the caudate nucleus was there a diffuse and even distribution of hemosiderin deposits within the adventitial cells and microglia. In the cerebral cortex strongly positive regions alternated with those in which the reaction was weak or entirely absent. This variation did not correspond to differences of the inflammatory changes. Regions with pronounced inflammation might be entirely free from iron deposits. Since the brain had been in formalin for a considerable time prior to the investigation, it is impossible to say whether the irregularity of the iron reaction was an abnormal feature of the case or merely due to the post mortem action of formalin.

Figs. 1-3 show the appearance of the pathological process in Nissl preparations taken from the frontal, parietal, and occipital regions at the same magnification. It is easily seen that while there was some degree of variation of the severity of the

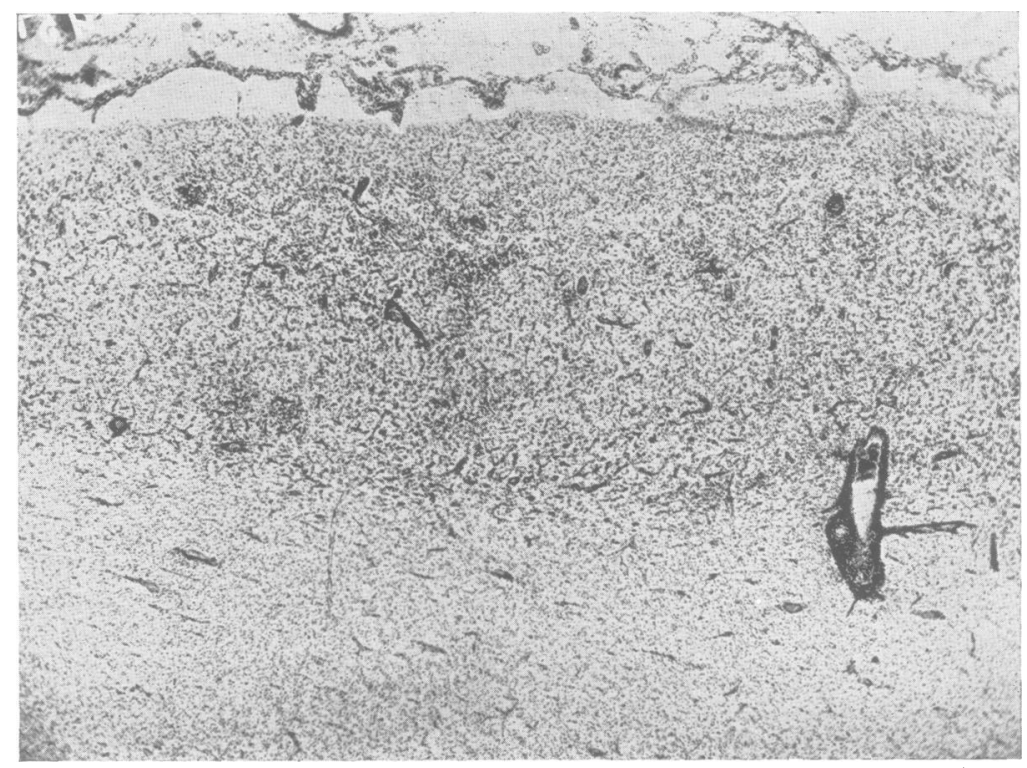

Fig. 1.-Frontal cortex, Nissl stain. $21 \times$.

lesions in the two former regions the occipital cortex was affected most intensely (Fig. 3, Figs. $4 a$ and $b$ ). The process was particularly severe in the parastriatal cortex, while the calcarine region, though not spared, was less involved. There were further interesting points of difference between the occipital regions and the rest of the cortex. Fig. 3 shows marked inflammatory changes in the deep white matter which was not affected in other regions with the exception of the superficial parts adjacent to the cortex which are commonly affected in the paretic process. Corresponding to the inflammatory changes in the white occipital matter, there was diffuse and patchy demyelination of a moderate degree (Fig. 5), fibrous gliosis (Fig. 6), and lipoidal breakdown products in fixed glial and adventitial cells and only occasionally in mobile compound granular cells. These lipoidal deposits stained brightly with Scharlach R (Fig. 7). No demyelination or formation of lipoidal breakdown products was seen anywhere else in the white matter, while a slight fibrous gliosis of the white matter was found also in other lobes of the brain. Inflammatory changes of the occipital cortex and white matter as well as demyelination and the formation of lipoidal breakdown products was fairly symmetrical on both sides. The demyelina- 


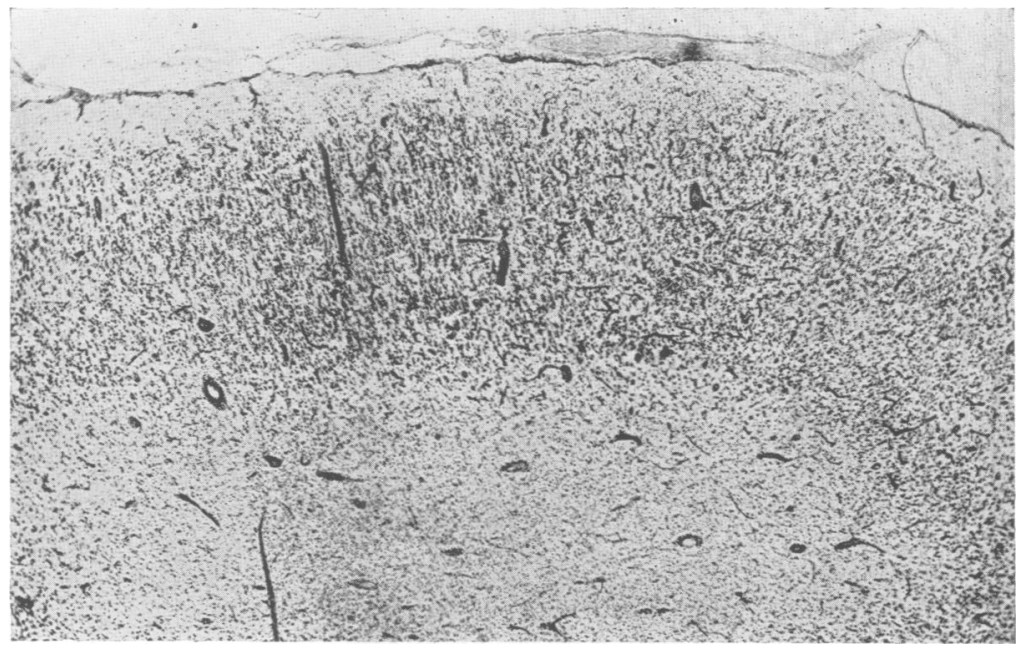

Fig. 2.-Parietal cortex, Nissl stain. $21 \times$.

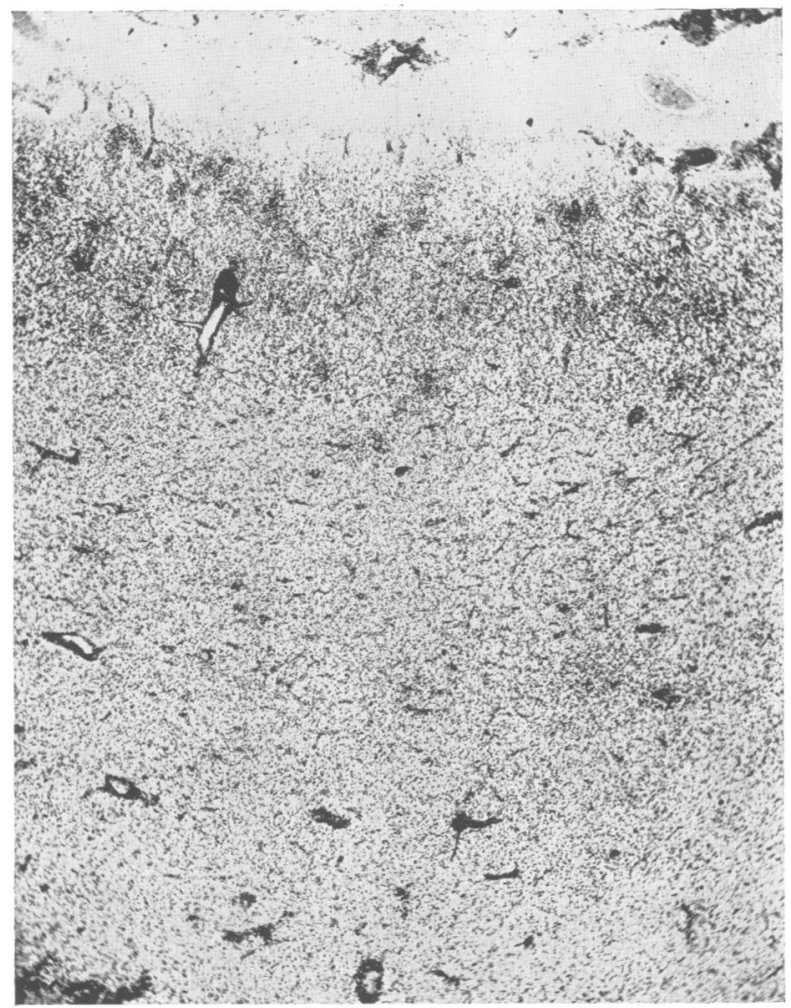

Fig. 3.-Occipital cortex, Nissl stain. $21 \times$. Note especially the marked perivascular infiltration within the deep white matter. 


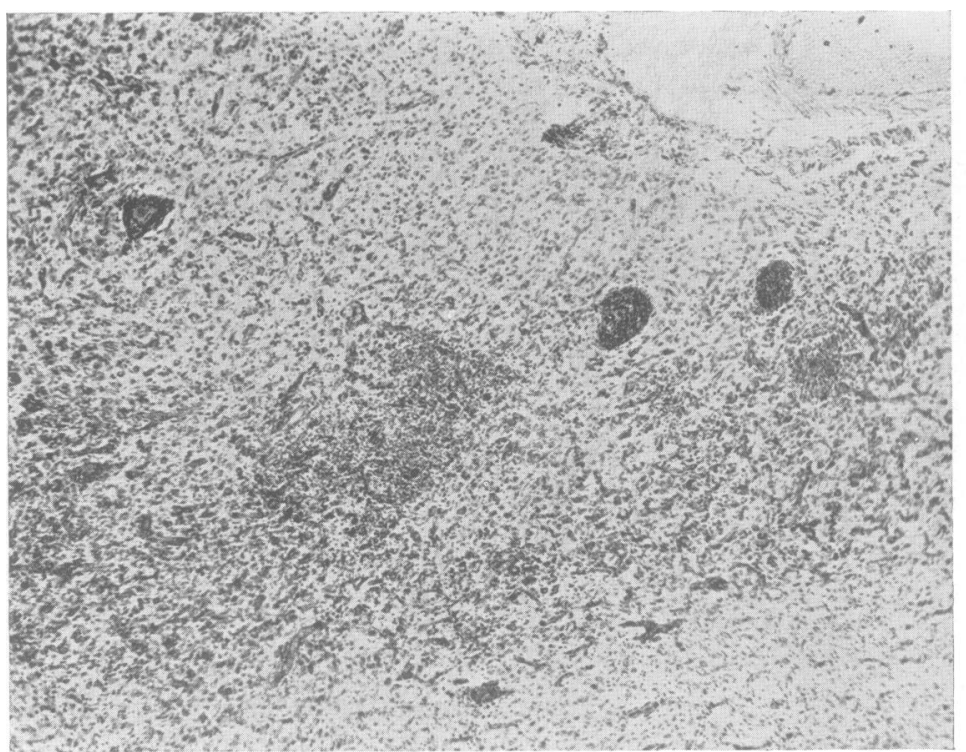

A

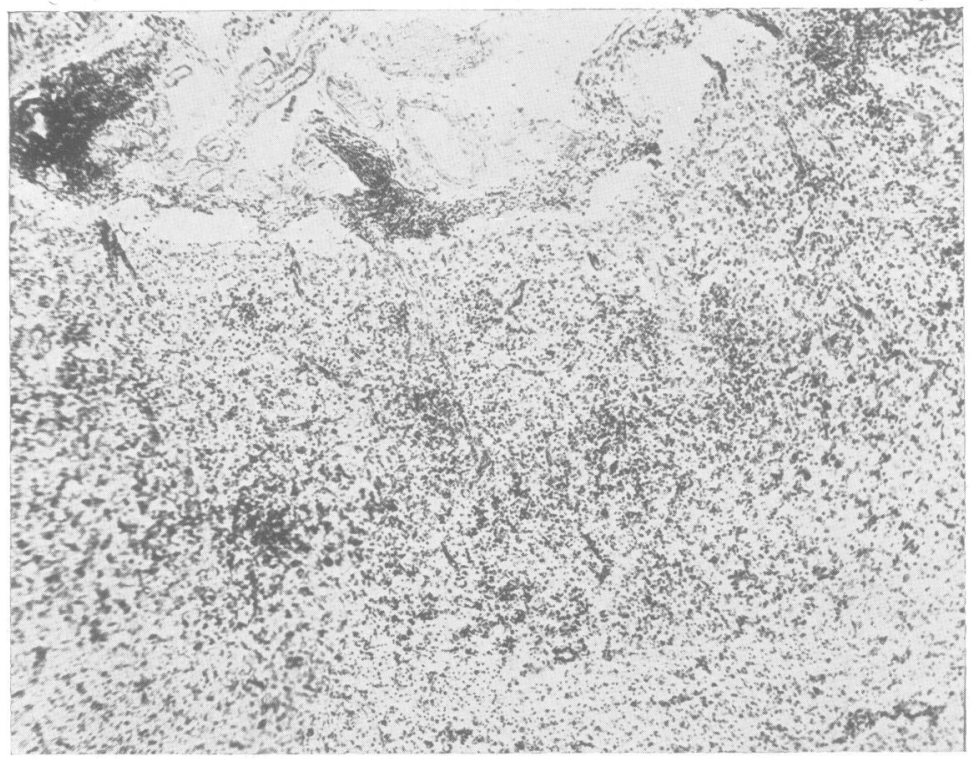

B

Fig. 4.-Occipital cortex, Nissl stain. $55 \times$. Showing, apart from perivascular infiltrations, massive cellular accumulations (mainly plasma cells).

tion to some extent involved the visual tract but there were no signs of degeneration in lower levels of the visual pathways.

The difference of the inflammatory changes in the occipital region as compared with other regions was not only quantitative. A significant feature in the occipital 
region was the disregard of the plasma cells and lymphocytes for the pioglial membrane. Some plasma cells lying outside the vessel sheaths were seen in other cortical regions, but it was exceedingly rare to find them in such numbers anywhere except in the occipital cortex. Some of the cellular accumulations which Fig. 4 demonstrates were almost entirely composed of plasma cells, and sometimes so densely packed as to simulate a plasmocytoma (Fig. 8) although this was, of course merely a superficial resemblance. In and around such areas the cytoarchitectonic structure of the cortex was more profoundly disturbed than in even the severest cases of ordinary G.P.I. Only a few surviving nerve cells were seen. Apart from these and the numerous inflammatory cells a large number of plump cells and actively proliferating blood vessel elements were the main constituents of the cortical tissue. There was a predeliction of these severe changes for the upper layers although occasionally they also occurred in the deeper layers. Nowhere had a spongiose state developed, but there was a distinct loosening of the texture of the so-called ground

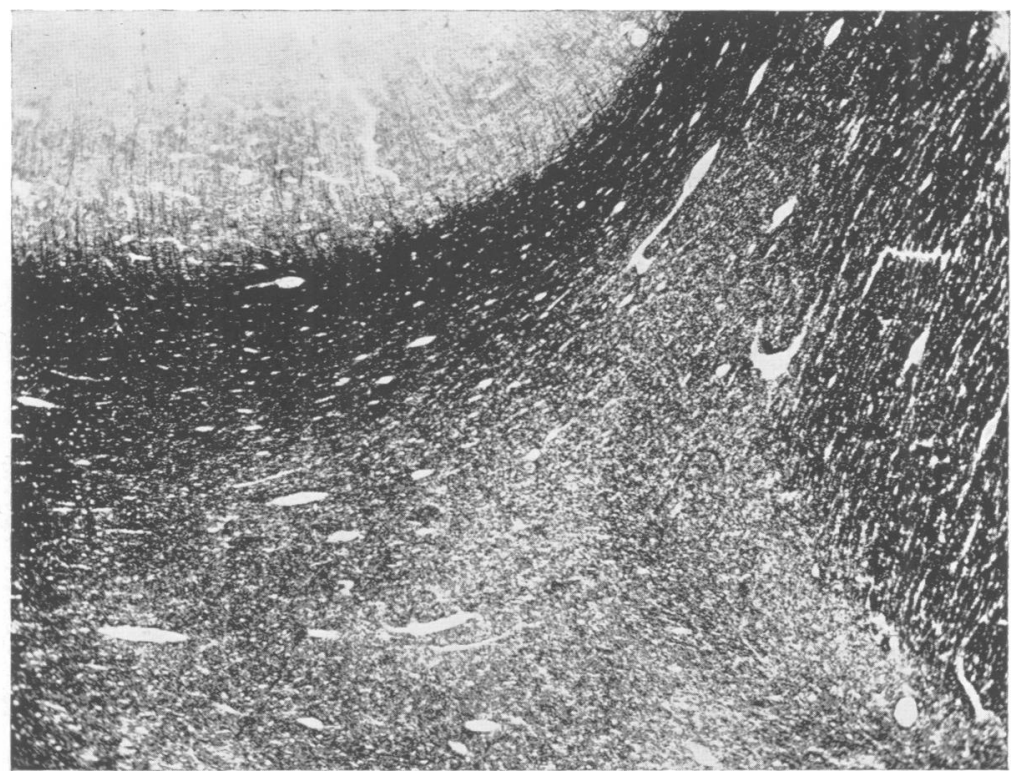

Fig. 5.-Occipital lobe, Weil stain for myelin.

substance. Despite the severity of the destructive process the fibroglial reaction was rather weaker and more irregular here than in the anterior cerebral regions apart from the plump cells which did not contribute appreciably to the production of glial fibres. In view of the general irregularity of the iron rection within the cerebral cortex nothing can be said about its special behaviour within the occipital lobe.

The type of nerve cell degeneration varied a great deal in all cortical regions. Some cells with enlarged pale nucleus, tigrolysis, and dendrites visible for long distances resembled acute swelling. In others the cytoplasm, after disappearance of the Nissl corpuscles, had become vacuolic and seemed to crumble away at the margin of the cell. In still later stages the swollen nucleus became structureless and disappeared. A fair number of nerve cells was seen in which the nucleus was excentric and the cell globular with the tigroid substance displaced towards the periphery or entirely absent. These cells corresponded to what has been described as "Zellblaehung" which is closely related to both retrograde degeneration and the cell change in Pick's disease. This type of cellular degeneration was somewhat more 


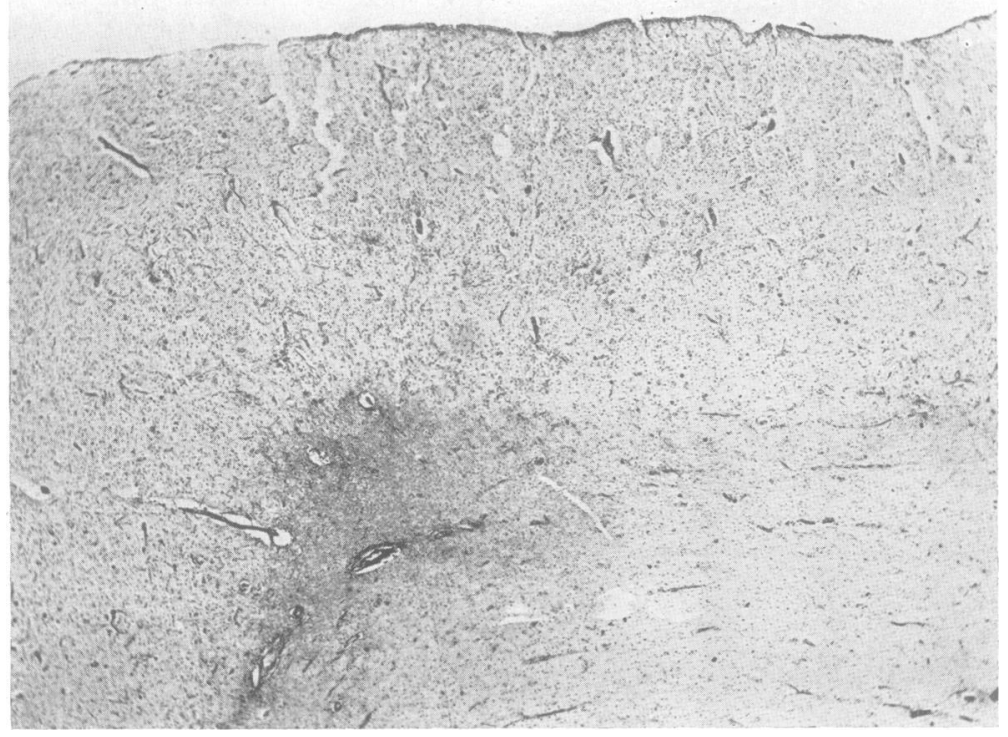

Fig. 6.-Occipital lobe, Holzer stain. Gliosis of the white matter.

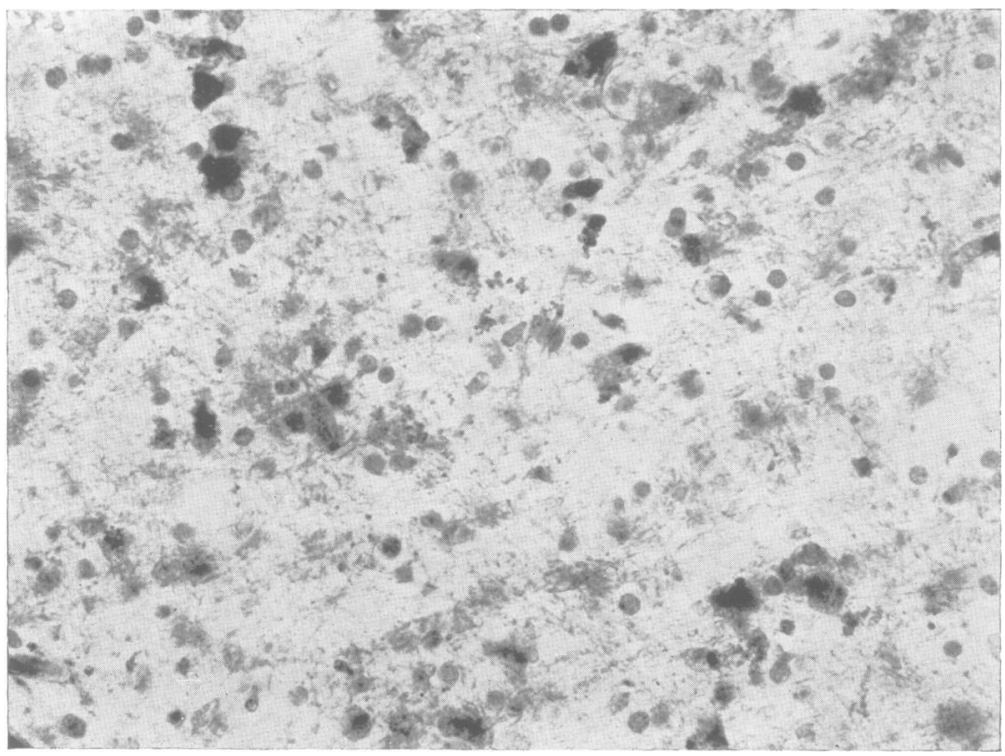

Fig. 7.-Occipital lobe, Herxheimer stain. $350 \times$. Showing lipoidal breakdown products mainly in fixed glial and adventitial cells. 
frequent in the severely damaged occipital areas, but it occurred also in other regions of the cortex. Bielschowsky stained slides did not reveal argentophil inclusions in these cells. Ischemic, homogenizing or Nissl severe change were not observed, nor were senile plaques and neurofibrillar thickening found in any part of the grey matter.

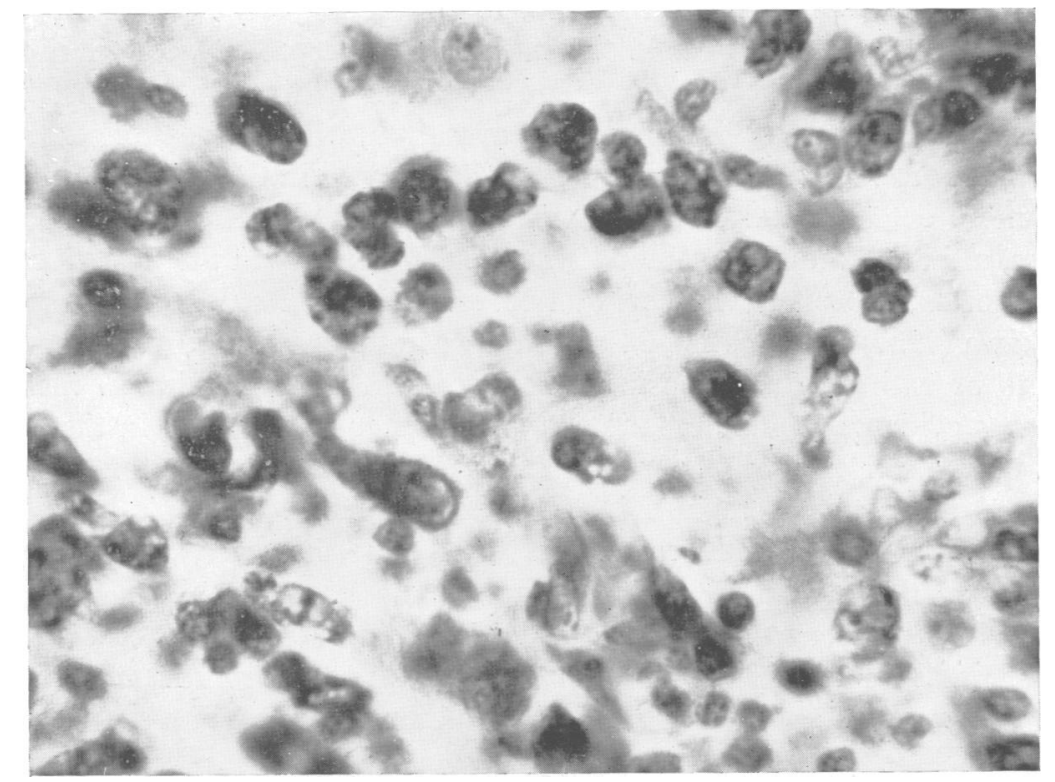

Fig. 8. Occipital cortex, Nissl stain. $1,100 \times$. Showing a plasma cell accumulation mainly outside the pia-glial membrane.

Numerous blocks from all parts of the cerebral cortex and the white matter were investigated for spirochætes but neither these nor other micro-organisms were found.

No signs of cerebral syphilis independent from the process of general paralysis were found. The frequently marked lymphocytic cell infiltrations around cortical vessels cannot be interpreted as miliary gummata as had been done on similar histological evidence by previous authors.

\section{Discussion}

Reviewing briefly the clinical history in the case which we have described, it will be seen that this patient's mental illness extended practically continuously over a period of 6 years (1931-37). Until 1934, when she was able to leave Bexley Hospital, her condition had been regarded as a psychotic reaction occurring in a rather unstable paranoid woman, consequent upon the untimely death of her husband. At this time (1934) there was no evidence of any organic cerebral disease, and the Blood W.R. and M.K.R. were negative. Three years later (1937) she was re-admitted to the Maudsley Hospital, and although the report on her condition, during the interval since her discharge from Bexley, did not suggest that her present condition was other than a relapse of her former psychosis, clinical examination revealed definite evidence of organic cerebral changes. The presence of an Argyll Robertson pupil, the organic 
nature of the psychosis which in some respects resembled a Korsakow syndrome, and the serological findings although not entirely typical (Paretic Lange curve and negative Wassermann), suggested that the patient was suffering from general paralysis of the insane, and the subsequent histopathological findings were also in favour of such a diagnosis. Without regard for the atypical distribution and the intensity of the process, the plasma cell infiltration, microglial reaction, and positive iron findings in the cortex and corpus striatum, could indicate no other condition, with the possible exception of a Trypanosome infection which can be disregarded in this case.

A more detailed analysis of the histopathological findings shows that the process, although diffuse, attained its maximum intensity in the posterior parts of the cortex, especially the occipital lobes. This in itself is most unusual. Funakawa (1927) investigating 34 cases of general paralysis found the occipital lobes to be entirely unaffected in seven cases. In the remaining 27 instances there was evidence of inflammation but to a lesser degree than in the frontal areas of the cortex. Similarly one of us (A. J. G.), at Horton Hospital, examined the occipital regions in 74 cases of general paralysis, and found inflammatory changes in 12 cases. In 11 of these, however, the infiltrations were of a mild degree and involved only the parastriatal areas. In the twelfth case the inflammatory changes were more pronounced but not exceeding those in the frontal lobes. The "posterior" distribution of the process in the case under review, together with the localizing clinical manifestations, suggested a possible relationship to the Lissauer type of general paralysis. This hypothesis, however, requires further examination and discussion, because both clinical and pathological findings, at first sight, do not conform to the generally recognized clinico-pathological syndrome associated with the name of Lissauer. Thus although "focal" manifestations pointing to a lesion in the parietooccipital regions were undoubtedly present (vide Dr. Mayer-Gross's report and the result of the electro-encephalogram), convulsions were not reported and various authors, e.g. Merritt and Springlova (1932) have stressed the diagnostic significance of convulsions, especially of the apoplectic variety. Nevertheless it would appear injudicious to exclude a diagnosis of Lissauer's Dementia Paralytica merely on the absence of seizures. The mechanism of convulsions is frequently obscure, and may depend to a considerable extent on the localization of intracerebral disease or injury, rather than on the nature of the process involved. Further, there does not seem to be any instance of Lissauer's Dementia Paralytica quoted in the literature, in which the typical local findings were entirely confined to the parieto-occipital regions. In most cases, at any rate, the occurrence of apoplectic seizures appears to be directly related to damage within, or in close proximity, to the "motor" areas of the cortex. If it be conceded that any case of general paralysis which shows definite localizing signs or symptoms be regarded as belonging to the Lissauer type, then there is ample justification for including our case in that category.

Of even greater interest, however, is the comparison of the pathological findings in this case with those generally observed in the Lissauer type. In the first place there were no localized areas of atrophy but the reason for this 
may become apparent by consideration of the histopathological clianges. There is no doubt that despite an absence of macroscopic atrophy in the occipital lobes, the process in this region differed significantly from the changes in other areas of the cortex. Elsewhere the inflammatory reaction did not exceed a moderately severe degree, as might be found in the average untreated case of general paralysis. In the occipital lobe the infiltrations assumed massive proportions, invading beyond the piaglial membrane, and involving also to a considerable extent the vessels of the deep white matter. Associated with this intense inflammatory reaction, there was gross destruction of the cortical elements, and areas of demyelinization in the white matter. The presence of numerous "plump" cells is of undoubted importance. Spielmeyer (1922) regards these cells as a criterion of rapid and abundant destruction, and they represent an abortive attempt at glial repair, similar to that found in Schilder's disease, and in cases of softening due to vascular injury. It is impossible to over-emphasize the degree of disintegration which had taken place in the occipital cortex in this case, and the significance of this fact becomes apparent when it is considered in relation to the findings usually described in the areas of local atrophy in Lissauer's Dementia Paralytica. Malamud (1937) expressed the general opinion when he states that status spongiosus is the essential lesion in these atrophic regions. Status spongiosus represents gross destruction, combined with an unsuccessful attempt at glial " repair," and Merritt and Springlova have pointed out that in status spongiosus the glial reaction is at first protoplasmic and later fibrous. The type of localized lesion in our case may at least be regarded as equivalent to status spongiosus on the grounds of localized destruction. It may lack the entire disappearance of the nervous parenchyma and substitution by a glial network, but it is quite feasible to suppose that it may represent a "pre-spongious" state. If the patient had not succumbed at this stage it is easy to imagine that the cortical destruction in the occipital regions would have proceeded to a state of entire disintegration, with more or less complete removal of the products of parenchymal destruction, the further development of the fibrous glial elements, and the subsidence of the inflammatory reaction. The absence of macroscopic atrophy has been noted, but if the condition had been allowed to mature in the way we have visualized, then there is little doubt that areas of local atrophy would have made their appearance in the occipital cortex.

Various theories have been advanced to explain the pathogenesis of Lissauer's Dementia Paralytica and the causation therein of status spongiosus. Lissauer and Storch (1901), and later Alzheimer (1904), considered that the changes within the areas of local atrophy were a direct expression of the process of general paralysis itself. Additional factors have been cited to explain the increased damage in the atrophic areas. Jacobs' (1929) theory that the lesion in Lissauer's Dementia Paralytica were due to organic vascular disease is now largely discredited because organic changes in the vessels are seldom observed. It might be worth mentioning that a variety of clinical syndrome which may simulate Lissauer's Dementia Paralytica is occasionally encountered, and corresponds to the cases described by Jacob. It consists of 
the co-existence of general paralysis and meningovascular syphilis. Endarteritis may lead to localizing symptoms and thus present the clinical picture of a Lissauer type. We have studied such a case and made a provisional diagnosis of Lissauer's Dementia Paralytica, but at subsequent histological examination it was obvious that the localizing lesions were the sequelæ of softenings in the white matter resulting from thrombosis in endarteritic vessels.

Fischer (1911) introduced a "toxic" element. Bielschowsky (1920) believed that a circulatory factor, namely, altered permeability of the cortical vessels, leading to a "serous soaking" of the tissues, was responsible. Sträussler and Koskinas (1926) also favoured Bielschowsky's theory, and more recently Merritt and Springlova (1932), following the vasomotor theories of Ricker and Spielmeyer, have postulated a circulatory factor of a rather different type. These authors regard the white matter destruction as the primary condition and suppose that it is caused by functional vascular changes (" atony or spasm ") intimately associated with the very constant occurrence of convulsions, which eventually lead to organic damage. Von Braunmühl $(1932,1933)$ has described the evolution of status spongiosus in terms of colloid chemistry, believing that an intrinsic factor (" endogenous predisposition ") is responsible for the metabolic changes which lead to its formation. Malamud (1937) agrees with Von Braunmuhl in regarding that the changes are due to a "synäretic" process, but while the latter maintained that the synäresis is endogenous and merely released by the inflammation, Malamud believes that a variety of exogenous factors-toxic, metabolic, inflammatory, and possibly others, are the direct cause of the alteration in the colloid state of the tissues. These theories, based on colloid chemistry, however ingenious and possibly indisputable, appear to render but little help in the elucidation of the problem. It is obvious that changes in the colloidal state of a tissue must take place during its disintegration, but the various factors which have been deemed responsible for the initiation of the destructive process, do not differ greatly from those which have already been under consideration without resorting to expression of their action in terms of colloid chemistry.

In considering the findings in our case in relation to these individual hypotheses, there would seem little doubt that the evidence is in favour of the original view held by Lissauer and Alzheimer. The process underlying the "focal" manifestations was essentially inflammatory-an extreme localized intensification of the "normal" pathological process of general paralysis. We have assumed that it represents an early stage, and the previously recorded findings in cases of Lissauer's Dementia Paralytica have invariably been those of later phases in the disease, when the inflammatory reaction has largely subsided. It is not surprising, therefore, that so many different theories have been evolved to account for the state of localized disintegration which would appear to have little direct relationship to the inflammatory phase. Yet it would be unwise to dismiss these other factors as of no pathogenic importance, because each or all of them may well arise during the course of the inflammatory process. For instance, the " toxic" factor mentioned by Fischer, and the "serous soaking" of Bielchowsky would be almost natural results of such 
intense inflammation. Edema of the tissues, hyperæmia, and endothelial swelling of the vessels would inevitably result in vascular stasis which would then have its added effect. In some cases there is unmistakable evidence of a vascular factor, such as ischæmic cell necrosis, and areas of softening as have been reported by Merritt and Springlova. But such findings are certainly not invariably reported in the cases published in the literature, and were not seen in our case. Of considerable interest in our case was the evidence of inflammation within the deep portions of the occipital white matter. This may well indicate that the white matter changes, considered to be the primary lesion and of vascular origin, by Merritt and Springlova, are also the direct result of the inflammatory process. If a vascular mechanism must also be postulated, then in this case at any rate it is likely to be secondary and not the primary condition. Reference has been made by Smith (1934) quoting Spatz, to "transitional" cases between ordinary general paralysis and Lissauer's Dementia Paralytica. The existence of such cases does not, of course, exclude the possible operation of additional factors, but must surely favour the assumption that the Lissauer type arises directly from the generalized paretic process.

If the inflammatory process itself is to be held responsible for the accentuated local damage in the Lissauer type, then naturally the role of the Sp. Pallida must be considered. In view of the negligible findings in the atrophic areas, spirochætes have not been held directly responsible by previous authors. It must be remembered, however, that if the condition has proceeded to a state of atrophy, with more or less complete subsidence of the inflammation, the absence of spirochætes should not necessarily permit any conclusion to be made with regard to their pathogenic insignificance. This would not apply to our case where intense inflammation was still present, but it is universally conceded that the failure to demonstrate spirochætes in about one-third of untreated cases of general paralysis is no proof against their direct action in these instances. It is well known (Jahnel (1918), Hermel (1921), Marinesco and Minea (1913), Levaditi, Marie and Bankowski (1913)) that spirochætes are most abundant in the ordinary type of general paralysis when patients die during paralytic seizures. In the light of this fact it seems strange that all previous authors should have discounted the possible significance of spirochætal action in the Lissauer type, in which convulsions are generally so prominent. We feel, therefore, that the problem of the $S p$. Pallida in Lissauer's Dementia Paralytica is as yet unsolved and merits further attention.

\section{Summary and Conclusions}

The necessity for caution and reserve in arriving at any conclusion on the evidence of one case has not been overlooked, but in this instance there are certain features which enhance its value as a single observation. For reasons which have already been discussed it is believed that an opportunity has arisen to study the Lissauer process at an earlier stage than has hitherto been recorded. The contribution which this case has made towards the elucidation of th pathogenetic problem in Lissauer's Dementia Paralytica, is that in this insta r.c 
at least, the evidence supports the original view of Lissauer and Alzheimer that the circumscribed lesions are essentially due to a local intensification of the paretic process.

Moreover, it demonstrates that the absence of apoplectiform or epileptic convulsions on the clinical side, and of macroscopic atrophy and status spongiosus from the pathological aspect, do not necessarily exclude a diagnosis of Lissauer's Dementia Paralytica. The desirability for a more detailed clinical analysis in cases of general paralysis, such as applied by Dr. MayerGross in this instance, becomes apparent. If such a procedure was universally adopted, it migh well reveal a higher incidence of the Lissauer type and particularly in the earlier stages, than previously supposed.

\section{Acknowledgments}

We are indebted to the Medical Superintendents of the Maudsley Hospital and Bexley Heath Hospital for the permission to publish the case and to make use of the clinical records. We owe thanks also to Dr. Nicol for his consent to refer to certain findings in other cases studied at Horton Hospital.

Preparation of the histological specimens and the microphotographs has been done by Mrs. E. Beck working at the laboratory under a Rockefeller Grant.

\section{REFERENCES}

Alzheimer, A. (1904). Histologische Sudien zur Differential/diagnose der progressiven Paralyse, in Nissl: Histologische und histopathologische Arbeiten ueber die Grosshirnrinde. Jena, Gustav Fischer, Vol. 1.

Bielschowsky, M. (1920). J. Psychol. Neurol. Lpz., 25, 72.

Braunmũhl, A. (1932). Z. ges. Neurol. Psychiat., 142, 1. (1933). Ibid., 148, 1 .

Buder, P. (1903). Allg. Z. Psychiat., 60, 534.

Dalke, M. (1938). Rev. Asoc. méd. argent., 52, 786.

Divry, P. (1939). J. belge Neurol. Psychiat., 39, 5.

Fischer, O. (1911). Z. ges. Neurol. Psychiat., 7, 1.

Funakawa, Y. (1927). Arch. Ophthal., 119, 270.

Hermel, H. (1921). Z. ges. Neurol. Psychiat., 73, 419.

Jakob, A. (1929). Anatomie und Histologie des Grosshirns. Leipzig, Franz Deuticke, vol. 2.

Jahnel, F. (1918). Z. ges. Neurol. Psychiat., 42, 21.

Levaditi, C., Marie, A., and Bankowski, J. (1913). Ann. Inst. Pasteur, 27, 576.

Lissauer, H., and Storch, E. (1901). Mschr. Psychiat. Neurol., 9, 401.

Malamud, N. (1937). Arch. Neurol. Psychiat. Chicago, 38, 27.

Marinesco, G., and Minea, J. (1913). Rev. neurol., 9, 581. (Vol. 25, No. 9.)

Merritt, H. H., and Springlova, M. (1932). Arch. Neurol. Psychiat. Chicago, $27,987$.

Ogino, R. (1936). Jap. J. med. Sci., 4, 23.

Smith, J. (1934). Med. Times, N.Y., 62, 372.

Spielmeyer, W. (1922). Histopathologie. Springer, Berlin.

Sträussler, E., and Koskinas, G. (1926). Z. ges. Neurol. Psychiat., 105, 5 5. 